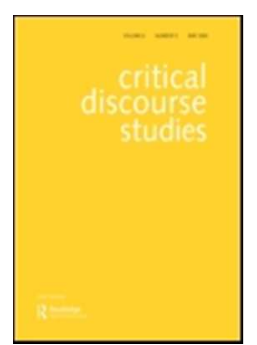

The topography of masculine normativities in South Africa

\begin{tabular}{|r|l|}
\hline Journal: & Critical Discourse Studies \\
\hline Manuscript ID & RCDS-2016-0114.R1 \\
\hline Manuscript Type: & Full Length Article \\
\hline Keywords: & $\begin{array}{l}\text { masculinity, South Africa, print media, hegemony, normativities, corpus- } \\
\text { assisted discourse studies }\end{array}$ \\
\hline \multicolumn{3}{|c}{} \\
\\
$\begin{array}{c}\text { SCHOLARONE } \\
\text { Manuscripts }\end{array}$ \\
\end{tabular}




\title{
THE TOPOGRAPHY OF MASCULINE NORMATIVITIES IN SOUTH AFRICA
}

\begin{abstract}
In this paper, we examine representations of masculinity in the English-language South African print media. Using both quantitative and qualitative techniques to interrogate a large corpus (18 million words) of English-language newspaper articles on masculinity that appeared in South Africa between 2008-2014, we investigate the ways in which different South African masculine types are positioned with respect to one another in the media and examine how these positionings draw on broader tropes of gender, race and social class that circulate in South African society. Ultimately, our goal is to provide a more nuanced picture of gender/sexual hegemony in South Africa that goes beyond a simple opposition between dominant versus subordinate forms of masculinity to explore the range of competing normativities in the region. In doing so, we also aim to contribute to debates about the role of norms and normativities in the theorizing of masculinity more broadly.
\end{abstract}

Keywords: masculinity, South Africa, print media, hegemony, normativities, corpus-assisted discourse studies

\section{Introduction}

The concept of hegemonic masculinity has been a cornerstone of research on men and masculinities over the past three decades (e.g., Connell, 1987, 1995). Recently, however, Connell's formulation of the concept has come under sustained critical scrutiny. These critiques have focused primarily on two components of the theory. The first involves the way in which Connell's conceptualization maps the ideological field of masculinity, and particularly her claim that the field is buttressed by two independent axes that can be separated analytically: hegemony-subordination, an ideological schema internal to the gendered order that hierarchically ranks different articulations of masculinity with respect to one another, and authorisation-marginalisation, an external schema that ranks types of men according to other locally meaningful criteria (e.g., race, social class). While agreeing with the basic principle that an analysis of masculinity requires consideration of both of these axes, recent studies have argued that hegemony-subordination and authorisationmarginalisation are not as independent as originally claimed. Baker and Levon (2016), for example, offer convincing empirical evidence that representations of masculinity in the British press always also involve simultaneous representations of race and class, thus demonstrating how hegemony/authorisation (and subordination/marginalisation) are often linked in that context. Based on these findings, Baker and Levon (2016) argue for the importance of more in-depth investigations of the intersectional and mutually constitutive relationship between the two axes rather than an a priori assumption of their independence.

The second major critique of hegemonic masculinity involves the theory's somewhat simplistic and undifferentiated treatment of power. Christensen and Jensen (2014), for instance, note how Connell's formulation conflates the power that certain articulations of masculinity may have over other men (what they term internal hegemony) and the power associated with the maintenance of patriarchy (or power over women, i.e., their external hegemony). Christensen and Jensen (2014) argue that numerous studies have demonstrated that internal and external hegemony need not go hand-in-hand, since some articulations of masculinity can subordinate others while not necessarily perpetuating patriarchy (cf. Hearn \& Morrell, 2012) while certain forms of subordinated masculinity can nevertheless reap a patriarchal dividend (cf. Milani, 2013; Baker \& Levon, 2016). In another critique, Ratele (2014) describes how most uses of hegemonic masculinity conflate the existence of power 
across different levels of social organisation, assuming that "powerful" men in one sphere are also powerful in others. According to Ratele (2014, pp. 38-39), this leads to:

an upside-down world (Ahluwalia, 2003). In such a world, marginal masculinities are mistaken for hegemonic ones. In such a world, 'traditional/ist men' are not necessarily hegemonic, and indeed may be marginal alongside poor and unemployed men, young men, gay men, and disabled men. In this world ... while there are exalted hegemonic notions of masculinity, these are complicated by the fact of marginalisation which characterises the lives of the majority of men's and boys' conditions. Therefore, the best we can speak of are marginal hegemonies, or hegemonies within marginality, as opposed to hegemonic masculinity tout court.

In order to overcome this, Ratele argues for a suppler understanding of power and hegemony, one that locates individuals within the full complexity of their lived experiences.

The upshot of these various critiques of the theory of hegemonic masculinity is that while the concept has been an analytically very useful one to date, current research needs to develop a more sensitive and fine-grained perspective for analysing the ways in which gender articulates with other axes of social differentiation, and thus produces different and often conflicting power configurations. And though this critique is relevant to a wide range of ethnographic contexts, it is particularly important in South Africa, a society that has undergone wide-ranging social and political upheaval in the past twenty years resulting from massive attempts to realign racial and socioeconomic orders. These changes have coincided with concomitant shifts in masculine gender norms, with scholars documenting a move from an idealised puritan masculinity under the apartheid regime (e.g., du Pisani, 2001), to the heroic masculinity of the struggle against apartheid and the early democratic dispensation (e.g., Unterhalter, 2000), and the strong masculinity that has emerged more recently, embodied in particular in the political figures of the current president Jacob Zuma and the leader of the opposition party EFF, Julius Malema (e.g., Ratele, 2006, 2008). Given these shifts, Morrell, Jewkes and Lindegger (2012) argue for the need to reinvigorate the study of hegemonic masculinities in the South Africa context. Though they recognise the problems with the concept, they argue that it 'still retains utility both for academics and activists ... [if] the realms (in relation to race, class and age) and levels (i.e., global, national, or local) of its use [are] specified and observed' (p. 25). In other words, Morrell et al. do not argue for abandoning the concept of hegemonic masculinity, but rather for a more fine-grained and empirically nuanced analysis of its various manifestations in South Africa.

In the current article, we provide a first attempt at this type of more granular analysis by examining the representation of different types of men and masculinities in a large corpus of South African print media. In doing so, we illustrate differentials in representational power that are linked to the ways in which the media imbue certain masculinities with positive values and others with negative ones. We begin in the next section with a brief overview of prior research on men and masculinities in South Africa. We then go on to detail the data and methods of the current analysis, before turning to a discussion of our findings and their implications.

\section{Men and Masculinities in South Africa}

Since South Africa's turn to democracy in the early 1990s, there has been an upsurge of academic work on men and masculinities. This growing scholarly interest has been explained by some (e.g. Morrell et al., 2012) as a result of the enshrinement of gender equality in the new democratic dispensation, and the concomitant emergence of discussions about crises of masculinity. Of course, as feminist scholars have warned in other contexts (e.g. Johnson, 
1997), one should be wary of references to "masculinity crises" and other troubles in a context of social transformation. However, there is no doubt that the official recognition of gender equality as one of the anti-discrimination pillars of the new Constitution entailed the beginning of a series of (re)negotiations of masculine norms and roles in the "new" South Africa. As a large body of anthropological and sociological research has convincingly illustrated, such pushes and pulls of masculinities took very different guises depending on the specific context of investigation and the intersection of race, class, and age (see e.g. Sideris, 2005; Walker, 2005; Decoteau, 2013; Luyt, 2013).

Whether reproducing or contesting the status quo, these negotiations of masculinity at the grassroots did not take place in a vacuum but happened in the context of a broader shift of masculine ideals as personified by black male politicians. The first democratically elected president Nelson Mandela embodied a "new" form of egalitarian masculinity that could promote gender equality without for that matter being perceived as "un-African" because of his heroic credentials in the struggle against apartheid. In contrast, his successor Thabo Mbeki, and subsequently, Jacob Zuma typified a counter-tendency to Mandela's gender egalitarianism. Zuma in particular, epitomizes a self-styled return to "traditional" masculinity, one that is unashamedly "heterosexist, patriarchal, implicitly violent and that glorified ideas of male sexual entitlement, notably polygamy, and conspicuous sexual success with women" (Morrell et al., 2012, p. 17; see also Oostendorp, 2015 for a multimodal analysis of media representations of Jacob Zuma).

Obviously, it is not only male heads of state that promote through embodiment certain models of masculinity. South African mainstream media also play a key role in circulating specific representations of men, and thus contribute to solidifying specific masculine "types" in the national imaginary. It is beyond the scope of this article to offer a comprehensive overview of the research on masculine representations in all media discursive outputs such as film (e.g., Stadler, 2008), advertisements (e.g., Milani \& Shaikjee, 2013) and online news (e.g., Disemelo, 2015). Because of the focus of the present article is on print-media, we focus in this section on a few key studies on national dailies and magazines.

Perhaps one of the first attempts at mapping a topography of masculinities in the South African print media is offered in a study of masculine ideals in the context of the growing men's lifestyle magazines (Viljoen, 2008). Through a qualitative analysis of five "glossies" (Men's Health, FHM, GQ, Maksiman, and Bl!nk), Viljoen concludes that, despite attempts to appeal to a broader audience across races, the three successful magazines (Men's Health, FHM and GQ) promote a masculine ideal that is globalised, cosmopolitan, but racially white. And whilst there are more vernacular masculine types promoted by the Afrikaans-medium Maksiman and the mainly black-targeted Bl!nk, "the financial failure of both of these magazines does seem to indicate that South African men still prefer to buy into a globalised and two-dimensional image of masculinity in the form of mainstream men's lifestyle magazines, as opposed to a more authentic, vernacular image of masculinity" (Viljoen, 2008, p. 336).

A complementary picture of the racialization of masculinities in print media emerges from a qualitative analysis of selected articles from the tabloid Sunday Times (Buiten \& Naidoo, 2013), which is mainly aimed at black audiences. Despite the newspaper's overt commitment to gender equality, Buiten and Naidoo illustrate the ways in which masculinity is constantly represented in conjunction with (hetero)sexual prowess and success with women, who are in turn portrayed as sexual objects for the actualization of manhood (see also Luyt, 2013). These problematic representations of men's sexualities go hand in hand with trivializations and even normalization of gender-based violence. This does not mean that there were no alternative discourses of masculinity in the newspaper. Men advocating for 
women's rights were indeed given space in the tabloid but were quantitatively in the minority.

By the same token, through content analysis of news reportage about men's health in the daily Sowetan, which targets primarily working-class, black audiences. Khunou (2013) show how such news reports promote the idea that masculinity is violent and hegemonic; working class black men are generally represented in a negatively homogenous way as either ignorant or avoiding health issues altogether. But it is not only black working-class masculinities that are depicted in a negative light; their middle-class peers are too, as emerges from a study critically investigating news representations of the so-called "new" black middle-class (Iqani 2015). Here black men are problematically portrayed as "suffering from a moral hollowness: they are materialistic, selfish, greedy, have betrayed the struggle, and cannot be trusted with a social democracy. They are consumers, not citizens" (Iqani, 2015, p. 12).

Read together, these studies give an indication of the pecking order of masculinities in the South African print media. While white masculinities seem to be paradoxically presented as the aspirational ideal in a non-racial South Africa, black men are consistently associated with problems such as ill health, heterosexual gender violence, or moral decadence in the context of conspicuous consumption. That being said, the qualitative nature of this scholarship does not lend itself to draw definite conclusions about the political economy of masculine representations and their values in the South African mediascape. It is precisely with a view to offering a more comprehensive picture of the intersections of masculinities with race and social class in the media that we decided to build and analyze a large corpus of newspaper articles from the South African mainstream press. It is to such corpus that we now turn.

\section{Data and Methods}

In order to understand competing normativities in masculine representations in South Africa, we make use of a mixed-method approach that combines both quantitative and qualitative techniques through which we interrogate a large corpus of South African newspaper articles on masculinity. To do so, we first built a reference corpus of all articles that appeared between 2008-2014 in twenty South African English-language broadsheet publications, using the online news database Lexis-Nexis. ${ }^{1}$ This database contains a variety of South African titles with an emphasis on quality broadsheets rather than tabloids. Most of these publications belong to two of SA's leading media conglomerates: Independent Newspapers Group and Avusa (TMG). All in all, the corpus is representative of English-language broadsheets published in the country that target a variety of constituencies across racial, geographic and social lines. Lexis-Nexis archives all types of articles in the publications, including news stories, editorials, letters and arts and culture pieces. The resulting corpus contains over 700,000 unique articles, totalling just under 142.8 million words.

In order to allow us to examine representations of men and masculinity specifically, we next extracted a masculinity sub-corpus from the larger dataset. This was done by identifying those articles from the full corpus that contained at least one of the search terms (or their plural counterparts) listed in (1). The words in (1) include both common address terms for men in South Africa (e.g., boet, bro, bru) and different masculine person-types that exist in the South African popular imagination (e.g., guy, oke). They were chosen based on our own experiences of these terms being perceived as relatively "neutral" terms of male selfand other-identification and representation, and based on discussions with undergraduate students at the University of the Witwatersrand in Johannesburg, South Africa. We did not include words such as tsotsi (thug), which while typically male-gendered, carry overt 
negative connotations. By using these terms to build our sub-corpus, we are able to hone in on discussions of masculinity in our dataset and explore the ways in which different types of men are represented and positioned (cf. Baker \& Levon, 2015, 2016). The resulting subcorpus contains approximately 90,000 articles with a total of 18.4 million words. ${ }^{2}$

\section{[INSERT TABLE 1 HERE]}

The masculinity sub-corpus was subjected to two types of corpus-based analysis: keyword analysis and collocation analysis. Both keywords and collocates provide a method for identifying implicit meanings within a body of texts. Keyword analysis is a statistical procedure that locates the words that are significantly more (or less) frequent in a given corpus than in some other corpus. In this way, keyword analysis provides a comparative measure of the "aboutness" of a set of texts (Scott, 1999), identifying what it is about their lexical content that makes them in some way distinctive (e.g., Xiao \& McEnery, 2005) and allowing analysts to extrapolate dominant discourses within the texts (e.g., Baker, 2004b). For example, in his examination of speeches made in the UK House of Lords both for and against equalising the age of consent for heterosexual and homosexual sex, Baker (2004a) identifies terms such as convention, rights and human as key in the speeches of those parliamentarians who support the equalising of consent, and terms such as buggery and gross indecency in the speeches of those who are against it. Based on these findings, Baker is able to argue for the existence of distinct discourses in the for versus against corpora, with proponents of changing the law drawing on discourses of human rights and equality while those against it rely instead on discourses of homosexual sex as dangerous, unnatural and criminal. As this example demonstrates, keyword analysis is a useful tool for identifying subtle differences in the lexical profiles of two corpora, and thus the ideological and/or attitudinal differences these profiles reflect.

As Baker (2004b) cautions, however, keyword lists only provide an initial indication of quantitative patterns of difference between texts. Interpreting those differences appropriately often requires further examination using other quantitative and qualitative methods. Principal among these other methods is collocation analysis, or an examination of the "characteristic co-occurrence patterns of words" (McEnery, Tono, \& Xiao, 2006, p. 56). The idea underlying collocation analysis is that the occurrence of a particular word-form is rarely, if ever, haphazard. Rather, the appearance of a particular word can often predict the local appearance of another based on structured patterns of lexical and semantic preference (Sinclair, 1998; Stubbs, 2009). For example, Sinclair (1998) describes how the word budge tends to co-occur with an implied or grammatical negative element to its left (wouldn't budge, refused to budge). This semantic preference is important because it demonstrates how the putative meaning of the word (i.e., to move) is not actually what the word is used to mean in practice. Instead, budge tends to be used to refer to those people or things that refuse to move (or be moved), and to evaluate that lack of movement negatively. This negative evaluation inherent in the use of the term budge represents the word's semantic (or discourse) prosody, i.e., the attitudinal meaning that the use of a particular word conveys (Stewart, 2010; Stubbs, 2009; Xiao \& McEnery, 2006). Similar to keyword analysis, the semantic prosodies revealed by collocation analysis (normally in conjunction with the inspection of expanded concordance lines) provide an indication of the dominant ideologies operating within a particular set of texts. The primary difference is one of scale: in keyword analysis, we get insight into the overall structuring discourses of a corpus, while with collocation analysis we can observe the discourses associated with particular lexical items. Together then, keyword and collocation analysis provide a powerful toolkit for uncovering the ideological frameworks that inform the texts under consideration. 
In the current study, keyword and collocation analysis were conducted in WordSmith Tools 6.0 (Scott, 2012). Two types of keyword analysis were performed. For the first, the masculinity sub-corpus (18.4 million words) was compared to the full reference corpus (142.8 million words) in order to generate a keyword list for articles on masculinity as compared to all English-language newspaper articles that appeared during the period. In addition to this "master" keyword list, individual keyword lists were also generated for each of the address terms in (1), above, by comparing only those articles containing the relevant word to all articles in the masculinity sub-corpus. Generating these additional lists allows us to examine potential differences in "aboutness" among articles that mention the different address terms. For all keyword analyses, frequency differences between the target corpus and the reference corpus were examined using the log-likelihood statistic with the p-value threshold set at $p \leq 0.000001$. Following Gabrielatos and Marchi (2012), identified keywords were then ranked by effect-size for analysis. For collocation analysis, DICE coefficients were calculated using WordSmith's default 5-word span on either side of the target word. In keeping with Baker and Levon (2015), DICE coefficients were chosen because they tend to favour medium-frequency collocates that are "content" words (e.g., nouns, verbs, adjectives), as opposed to other measures that favour high-frequency "function" words (e.g., loglikelihood) or low-frequency words (e.g., Mutual Information scores). Finally, it is important to note that, unlike previous studies of representations of masculinity (e.g., Baker \& Levon, 2016), we intentionally avoid searching for collocates of specific demographic categories (e.g., "black man", "working-class man"). We do this so as to escape the imposition of any racial or class-based interpretations, preferring instead to allow the intersections between gender and other relevant social categorisations to emerge "bottom-up" from the data. We return to this point in our discussion below.

\section{Results}

Masculinity in (Anglophone) South Africa

We begin with a first keyword analysis of the entire masculinity sub-corpus. The top 75 keywords (as determined by the percent difference effect-size measure; Gabrielatos \& Marchi, 2012) are presented in Table $2 .^{3}$ There, we see that articles within the masculinity corpus tend to focus on three main themes, or semantic domains: sports, violence and crime, and kinship. Subsequent concordance analysis of these keywords, however, reveals that the terms in the kinship domain are in fact also related to the theme of violence and crime (with, for example, girl collocating predominantly with terms like rape, or male collocating with terms like suspect). What emerges, then, from an initial examination of keywords for the masculinity corpus is a bimodal conceptualisation of men and masculinity in South Africa. On one hand, there is the image of the South African sportsman, a highly salient cultural figure in the local cultural imagination. Among the Sports keywords in Table 2, we find names of popular rugby (e.g., Springbok, Stormers, Cheetahs) and football [soccer] (e.g., Sundowns, Pirates) teams, as well as terms associated with these and other sports (e.g., wickets, goals, side, game).

\section{[INSERT TABLE 2 HERE]}

The centrality of sports to normative articulations of masculinity has been well documented (e.g., Burstyn, 1999; Connell, 1995; Messner, 1992), including in South Africa specifically (e.g., Bhana, 2008; Mager, 2005). It is therefore not surprising to find keywords relating to sports featuring so prominently in our corpus. The same can be said for the other primary semantic domain we identify: violence and crime. Argued to be a hallmark of 
dominant conceptualisations of contemporary masculinity (Messerschmidt, 1993; Newburn \& Stanko, 2013), topics related to violence and crime also feature heavily in our South African corpus, with keywords such as rape, magistrate, robbery and suspect all identified (cf. also Pearce, 2008). What is, however, somewhat surprising about the keywords we identify is the lack of any reference to positions of (political) power or status, the lack of reference to sexuality or romance (except when in conjunction with violence, i.e., rape), and the general lack of any positive or valued personality characteristics (such as honesty or intelligence; cf. Romaine, 2001). Terms related to power/status, (heterosexual) romance, and valued character traits have been consistently identified in research on masculinity in North American and Northern European contexts (e.g., Baker, 2010; Caldas-Coulthard \& Moon, 2010; Romaine, 2001). The lack of such terms in our top keyword list thus provides a preliminary indication of an important difference in how masculinity is conceptualised and discussed in South Africa (though we concede there are limitations to how much information a keyword analysis can provide in this regard).

\section{[INSERT TABLE 3 HERE]}

This difference is further illustrated by an examination of the top collocates in our corpus of general terms relating to masculinity in the sub-corpus (see Table 3). Beginning with masculinity, we find fairly standard collocates of similarity (e.g., man) and opposition (e.g., femininity). We also find collocates, like violence, that are reminiscent of the general patterns identified in Table 2. But what is interesting about the results in Table 3 is the way in which the top collocates include a recognition of masculinity as something that is variable, associated with different notions and cultural constructions. An examination of individual concordance lines demonstrates that these notions and constructions, while often highly problematic, are not natural but are instead cultivated and perpetuated, as illustrated in (2):

(2) Drawing from Xhosa and Western dress, he creates his sculptural rubber artworks with pink ribbon trimmings to engage with the visual structures that perpetuate notions of masculinity. (Sunday Independent, 2009)

The impetus of his work lies in the deconstruction of regimes of truth, in notions of masculinity, the environment or belief itself, in order to access the real. (Business Day, 2011)

We have all experienced this form of socialisation, this pressure to conform, to adhere to toxic notions of masculinity. (Mail \& Guardian, 2012)

The challenge then becomes how to move the debate on gender-based violence from being one about women as victims and keeping them safe, to one that deals with the constructions of masculinity that make violence possible. (Cape Times, 2014)

In addition to the idea that masculinity is itself a construction, the collocates in Table 3 and the brief extracts in (2) also highlight how masculinity is generally perceived in fairly negative terms in the sub-corpus, associated with issues and crisis, many of them related to specific cultural traditions and beliefs. From a comparative perspective, the view of masculinity that emerges in South Africa is one that is both more nuanced and more negative than that which has been found in other contexts (cf. Baker, 2010; Caldas-Coulthard \& Moon, 2010). 
In contrast to masculinity, collocates for manhood reveal a more physical dimension to the concept, and specifically point to the practice of ritual circumcision. This practice is evoked by terms like passage, rite, initiation, transition, and it is associated specifically with Xhosa men (and boys). While perhaps seemingly innocuous, inspection of references in the corpus to rites of passage into manhood reveals that these rites are often depicted as backwards and potentially dangerous:

(3) It is important to speak out against the high number of deaths and genital amputations that have become a common feature of the annual rite of passage to manhood, due mainly to unhygienic and inhospitable conditions. (Sunday Times, 2010)

At the same time, initiation rites are also described as crucial to the achievement of successful (black) masculinity:

(4) When a boy turns 18 , he is considered ready to go to initiation school - it is his passage to manhood. There he gets taught how to behave like a man ... For Xhosa people, circumcision represents manhood. An uncircumcised male cannot be heir to his father's wealth, cannot marry or officiate in tribal rituals. Therefore, it is a huge celebration because the son is no longer a boy but a man and this, by all means, needs to be celebrated. It is a time to celebrate a new life because the life the son previously lived should be forgotten. (The Herald, 2014)

The semantic prosody of manhood in the corpus is thus an ambivalent one. Its collocates reflect both a concern with the unhygienic nature of this pre-modern ritual while simultaneously promoting the notion of initiation as a crucial passage on a boy's journey through life. Yet abstracting away from their content, what the collocates of manhood succeed in doing is placing an emphasis on the physical characteristics (and alterations of those characteristics) of black male bodies. In doing so, discussions of manhood in the corpus reproduce common tropes of black masculinity (in South Africa and elsewhere) as being focused on the body, and more particularly the penis (e.g., Milani, 2013). In other words, whether ritual circumcision is portrayed in a positive or a negative light, we see that manhood is understood as a physical phenomenon and that this physicality is associated exclusively with black men.

Our examination of the top keywords in the masculinity sub-corpus and the top collocates of the general terms masculinity and manhood help us to uncover the basic contours of the ideological field of masculinity in the South African context (Baker \& Levon, 2016). We find that, as a concept, masculinity is seen as something variable and subject to change, with a clear indication that it is connected to some troubles. A clue as to the kinds of problems involved is apparent in the prominence of terms linked to violence and crime throughout the sub-corpus, while the pervasive references to sports serve to reproduce a familiar association between masculinity and physical power. Interestingly, explicit references to embodied physical masculinity only appear in the context of the term manhood, where this concept is also overtly racialized as pertaining exclusively to black men. Overall then, what emerges is a general picture of South African masculinity as an articulated and contingent concept, one that varies across cultures. Moreover, and somewhat surprisingly given previous research, it is not a concept that is associated with overwhelmingly positive traits, and, as both the keyword and the collocation analyses demonstrate, is instead depicted as a frequent source of conflict and tension.

Types of South African Men 
In this section, we turn to an examination of how different types of South African men are representationally positioned within the ideological field of masculinity described above. Drawing on the method developed in Baker and Levon (2016), we do this by examining labels and address terms for different culturally recognised types of men within the subcorpus.

Table 4 presents the top collocates of the three most common male persona types in the data: man, guy and bloke. Of the three, man functions as the most generic term. It predominantly collocates with words referring to what van Leeuwen (1996) terms "identification categorization", or those processes through which individuals are classified according to their group memberships, their relations to others and their physical characteristics. In the current dataset, these include terms like old, young, black, and white (what van Leeuwen 1996 would call "classifiers"); forms such as family, boys, and woman (van Leeuwen's "relational" markers); and a sole instance of a "personal" qualifier: good. The categorization of man (and, hence, men) in terms of their age, provenance and race parallels what has been found in other contexts. Caldas-Coulthard and Moon (2010), for example, found that in the UK print media, men were most often described in terms of their age (e.g., "young", "old") and status (e.g., "poor", "rich"). They also, found, however that men in the British press were consistently described in terms of various positively valued behavioural characteristics, such as "compassionate", "charming", "generous" and "brave". Similarly, Baker (2010), in his diachronic investigation of four corpora of British English from the 1930 s to the 2000 s, finds the term man consistently associated with such positive adjectives as "celebrated", "distinguished", "wealthy", and "famous". In Table 4, the only potentially positive adjective is the fairly neutral good. Instead, and unlike the results of these previous studies, we find top collocates referencing criminal behaviour (killed, allegedly, arrested, shot) as well as some generic references to sports (match, squad). Examining the collocates of man in our corpus thus supports our arguments above regarding the differing conceptualisations of men and masculinity in South Africa versus other locations examined in the literature.

\section{[INSERT TABLE 4 HERE]}

This is not to say that positive traits are never associated with male types in our corpus. Instead, we see in Table 4 that they are restricted to guys and blokes. Of the two, guy is the broader term, collocating with more general categorization terms (white, black, little, old) and more specific appraisals (funny, great, tough). For bloke, appraisals predominate, and all of them reflect socially valued characteristics: nice, uncomplicated, ordinary, easygoing, salt-of-the-earth:

(5) Thursday was the time of Johnson, a quiet, unassuming bloke from Townesville, deep in northern Queensland - "real cowboy country" was how one local described it, the last place you'd expect to find a future fast bowler. (The Star, 2008)

Arthur is a down-home bloke whose metier is coaching. By all accounts he doesn't play the political game very well because he's not well versed in it. (Sunday Times, 2008)

To take on board the idea that he is not, after all, a culturally charged Zulu warrior but just an ordinary bloke in a grey suit is not going to be easy. (Pretoria News, 2009) 
I played with Ackies here at the Sharks and he is a salt-of-the-earth bloke. (The Mercury, 2013)

The example extracts in (5) demonstrate how in the corpus, a bloke is most often represented as an "authentic" or "natural" type of man. He is not someone who stands out in a crowd (just an ordinary bloke in a grey suit) or who engages in strategic or manipulative behaviour (he doesn't play the political game). Apparent in the examples in (5) as well is a racialized component to this characterization. Three of the four extracts refer to sports figures, and more particularly to rugby and cricket. In the South Africa context, rugby and cricket are both seen as associated with white communities (Afrikaans and English, respectively), whereas football is stereotypically the "black sport". The preponderance of the term bloke in reference to rugby and cricket, therefore, has the effect of racializing the term, of restricting the perceived reference of bloke to white South African men. And it is this form of white masculinity that is depicted as being nice and ordinary, as salt-of-the-earth. This racialization is apparent in the example from Pretoria News in (5), where the ordinary bloke is juxtaposed with the figure of the culturally charged Zulu warrior, the ideological opposite of default white "normality". 4 While more perhaps implicit than in other contexts (cf. Baker \& Levon 2016), our analysis of bloke and guy in the corpus reveals a distinct racial element, and highlights the tightly imbricated nature of representations of gender and race in South Africa (see also Viljoen 2008 for the connection between whiteness and ordinariness; and Milani \& Shaikjee 2013 for the racialization of sport in South Africa).

\section{[INSERT TABLE 5 HERE]}

This imbrication is also apparent when we examine the use of various address terms in the sub-corpus. Because of their relatively infrequent occurrence in newspaper discourse (appearing predominantly in letters, opinion pieces, and reported speech), address terms are examined via keyword, rather than collocation, analysis (as described above, keyword lists were generated by comparing only articles containing the address terms to the entire masculinity sub-corpus). Table 5 presents a keyword analysis of the terms boet, bru and bro in the dataset. Boet and bru are colloquial address terms widely used in South Africa that are derived from Afrikaans words for "brother". Bro is a similar type of word, derived from English. Despite their differing origins (i.e., Afrikaans versus English), all three terms are very common in South Africa, and are used frequently when speaking (or writing) in English. In Table 5, we see that both boet and bru tend to appear in more light-hearted pieces, particularly those involving sports and other kinds of leisure events. Rugby, stadiums, competitions and Springboks (the South African national rugby team) are all keywords, as are terms like braai (outdoor barbecue), weekend and farm. Perhaps unsurprisingly given the Afrikaans origin on the word, there is a definite Afrikaans flavour to the text, evoked by either explicit reference, e.g., Afrikaans, howzit (an Afrikaans-derived salutation) or more implicitly, e.g, farms and other canonical Afrikaans cultural references. The same can be said for texts containing bru, where we find consistent reference to a variety of pleasurable activities (theatre, surfing, festivals) and to specifically Afrikaans exclamations of approval (lekker).

In contrast, bro appears almost exclusively in texts dealing with more "serious" issues, including the economy (growth, economy, sector, budget, businesses), politics (Mbeki, election, commission, policy) and national infrastructure (investment, Eskom, electricity). This is unexpected, given the term's very colloquial and informal connotations. As in the US, one would not normally expect to be called "bro" in the context of a more formal discussion 
about politics or the state of the economy. To try and understand why bro appears in these contexts, it is useful to examine representative extracts from articles where it occurs:

(6) Greg Mills' article on graft in Kenya smacks of a typical Western journalist who jets into an African country for a week, suddenly becomes and expert, and then, unfortunately, influences millions of his readers back home. I was expecting something different from an African journalist. The column reads as if Kenya had made little or no progress over the past 50 years. I'll be the first to admit that what you wrote was correct, but I would also have liked you to give a more balanced perspective. You made no mentions of the strides that the country has made or are taking with themselves into the election. As Africa, we have enough enemies without; we don't need any more within. C'mon, bro, get on our side - objectively. Tell the balanced truth. (Sunday Times, 2013)

But the masterpiece [of unwitting racism] is from David Bullard's apology for his racist column: "the use of the term 'simple tribesmen' was never intended to imply stupidity but to suggest an uncomplicated lifestyle." Yeah, right, same difference. My advice is: get a personal editor, bro. Writing sensibly about race is tricky business, as you would have noticed. (Business Day, 2008)

Both of the extracts in (6) feature readers addressing columnists directly, and criticizing some aspect of the columnists' work. In both cases, moreover, what is criticized is directly relevant to racial differences between the columnists referenced (who are both white South Africans) and the authors of the letters (who elsewhere in their letters make clear that they are black South Africans). In the extract from the Sunday Times, the letter writer makes clear that he is displeased with Greg Mill's representation of the situation in Kenya, arguing that Mills provides an external (i.e., un-African) perspective. He concludes his comment with the imperative C'mon, bro, get on our side, establishing an explicit contrast between that which is truly African and that which is not. Similarly, in the extract from Business Day, the letter writer decries instances of casual and unwitting racism, including David Bullard's repeated conflation of traditional "tribal" lifestyles with lack of intelligence or access to modernity. She, too, concludes her comments with an imperative instruction to get a personal editor, bro. The term bro in these extracts thus functions as a tool for dismissing or demeaning the individual interpellated by the form. In essence, the authors of the letters are drawing on the connotations of informality associated with the term to position themselves as authorities on the topic, able to instruct someone less knowledgeable in appropriate forms of behaviour. We argue that it is not incidental that, in these and other cases, bro is also consistently used by black South African authors to address white interlocutors in this kind of dismissive fashion. In effect, we suggest that what the authors are doing with bro is instrumentalizing the stereotypical connotations of the form as an element of black vernacular speech (a connotation that exists in South Africa, like in other English-speaking locales) and using it as a way to distinguish between themselves - insiders - and their white addressees, who by implication are positioned as outsiders. Ultimately then, bro ends up labelling a form of white subjectivity in the corpus, but a very different one than the more "ordinary" (hegemonic) articulation referenced by guy and bloke.

\section{Summary and Conclusion}

Our goal in this article has been to provide an initial empirical examination of different forms of masculinity within the intersectional reality of contemporary South Africa. Our examination of how men and masculinity are represented in the English-language South 
African print media reveals that masculinity as a general concept is perceived as somewhat more variable and potentially problematic in South African discourse than what has been reported for other (predominantly European) sites (e.g., Baker, 2010, 2014). ${ }^{5}$ In particular, characterisations of masculinity as related to status, prestige and other positively valued traits are largely absent in our sample. Instead, we find a focus on violence, crime and (via the prism of sports) physical toughness. This variability in conceptualisations of masculinity is, moreover, stratified in terms of race, with white masculinities (GUY, BLOKE, BOET, BRU) associated with "ordinariness" and culturally valued characteristics ("laid-back", "salt-of-theearth") and black masculinities (MANHOOD) associated with problems and "traditional" ritual practices (see also Khunou, 2013). While this racialization of masculinity is more implicit in our data than in other contexts (cf. Baker \& Levon, 2016), its effect is to reproduce long-standing South African racial hierarchies, with white masculinity positioned at the normative moral centre and black masculinity on the potentially deviant periphery.

Overall, we find compelling evidence for the tight imbrication of masculinity and race in English-language South African media discourse, and for the hierarchical representational ranking of racialized male types in relation to one another. This finding resonates with claims made in earlier studies about the impossibility of examining the hegemony-subordination axis of masculinity on its own since authorisation-marginalisation always also plays a role (e.g., Baker \& Levon, 2016). In addition, this finding underscores Ratele's (2014) arguments about the need for a more nuanced and articulated understanding of hegemonic power. The negative representation of black masculinities in the corpus as being both physically threatening and morally deviant is not new (see Buiten \& Naidoo, 2013; Khunou, 2013), and is a clear illustration of Ratele's concept of marginal hegemony, where power in one domain is clearly circumscribed and constrained by the lack of power in another (cf. also Christensen \& Jensen, 2014). It is interesting that we find no real evidence for competing conceptualisations of (hegemonic) black masculinities in our data, such as the urban black man or rural African man described by Morrell (1998). This could be due to the quantitative method employed in the current analysis (which tends to highlight more dominant discourses in the data; see Baker \& Levon, 2015), and the fact that we only consider the English-language press. Analyses of masculinity in other languages, particularly isiXhosa and isiZulu, could provide a more comprehensive picture. For the moment, however, our analysis of English-language media demonstrates that dominant ideas about masculinity in South Africa remain tightly intertwined with ideologies of race. Are we stating the obvious? Working on discourses of unemployment, Mautner (2009, p. 128) argues that

Detractors of corpus-based methods could argue, of course, that one hardly needs a huge database of text and sophisticated software to 'prove' that being unemployed is not a pleasant thing. On the other hand, we should not forget [...] that a fair proportion of any empirical work is devoted, precisely, to finding evidence for the intuitively obvious.

Thus while perhaps obvious, our findings on the basis of corpus linguistic techniques provides part of the quantitative, empirical detail necessary for understanding how hegemonic masculinity operates in present-day South Africa (cf. Morrell et al., 2012), and helps to reveal the latent ideologies that undergird it. Theoretically, these results also point to the necessity of an intersectional approach not only to the analysis of gender and masculinities in particular, but also to critical discourse studies more broadly, pointing to the mutual constitution and imbrication of different social categories in the (re)production of specific representational power relations. 
Notes

1 The 20 publications are: Business Day, Cape Argus (and Cape Argus Weekend), Cape Times, Daily Dispatch, Daily News, Mail \& Guardian, Post, Pretoria News (and Pretoria News Weekend), Sowetan, Sunday Times, Sunday Tribune, Sunday World, The Herald, The Independent on Saturday, The Mercury, The New Age, The Star, The Sunday Independent, The Times, The Weekender. For the The New Age, data is available from 2011-2014; for Mail \& Guardian, data is available from 2010-2014; for The Weekender, data is available from 2008-2009. For all other publications, data is available throughout the study period (2008-2014).

2 It is important to note that our analysis of different "types" of South African men that follows is necessarily restricted by the fact that we consider only the English-language print media. We are currently conducting similar research on representations of masculinity in both the Afrikaans and isiZulu press. For the moment, however, our results are confined to the Anglophone print media in South Africa.

3 Only the top 75 keywords are chosen in an effort to restrict our analysis to those terms that occur with at least a minimum amount of frequency in the corpus, and thus enhance the representativeness of our interpretations.

4 Keyword analyses of the terms bloke and guy further understood the racial connotations of both words. In both cases, bloke and guy appear overwhelmingly in the context of articles about rugby and cricket, with top keywords including TEST, CRICKET, GAME, BOKS, BLACKS, BALL, PROTEAS, etc.

5 A reviewer notes that in comparing our results to those found in Europe, we may inadvertently perpetuate a view of Northern understanding of masculinity as normative. We take the point. Nevertheless, we think such a comparison is important given the predominance of Northern perspectives in masculinities research, and the assumption that these perspectives are in a certain sense universal. We hope that highlighting differences that exist in our data serves as a useful corrective to this universalizing tendency.

\section{References}

Ahluwalia, P. (2003). Fanon's Nausea: The Hegemony of the White Nation. Social Identities, 9(3), 341-356. http://doi.org/10.1080/1350463032000129966

Baker, P. (2004a). "Unnatural Acts": Discourses of homosexuality within the House of Lords debates on gay male law reform, Journal of Sociolinguistics, 8(1), 88-106.

Baker, P. (2004b). Querying keywords: Questions of difference, frequency, and sense in keyword analysis. Journal of English Linguistics, 32(4), 346-359.

Baker, P. (2010). Will Ms ever be as frequent as Mr? A corpus-based comparison of gendered terms across four diachronic corpora of British English. Gender \& Language, $4(1), 125-149$.

Baker, P. (2014). Using corpora to analyse gender. London: Bloomsbury.

Baker, P., \& Levon, E. (2015). Picking the right cherries? A comparison of corpus and qualitative analyses of news articles about masculinity. Discourse \& Communication, 19(2), 221-236.

Baker, P., \& Levon, E. (2016). “That's what I call a man": Representations of racialized and classed masculinities in the UK print media. Gender \& Language, 10(1), 106-139.

Bhana, D. (2008). "Six packs and big muscles, and stuff like that". Primary school-aged South African boys, black and white, on sport. British Journal of Sociology of Education, 29(1), 3-14.

Buiten, D. \& Naidoo, K. (2013). Constructions and representations of masculinity in South 
Africa's tabloid press: Reflections on discursive tensions in the Sunday Sun.

Communicatio, 39(2), 194-209.

Burstyn, V. (1999). The rites of men: Manhood, politics and the culture of sport. Toronto: University of Toronto Press.

Caldas-Coulthard, C., \& Moon, R. (2010). "Curvy, hunky, kinky”: Using corpora as tools for critical analysis. Discourse \& Society, 21(2), 99-133.

Christensen, A.-D., \& Jensen, S. Q. (2014). Combining hegemonic masculinity and intersectionality. NORMA: International Journal for Masculinity Studies, 9(1), 60-75.

Connell, R. W. (1987). Gender and power. Cambridge: Polity Press.

Connell, R. W. (1995). Masculinities. London: Polity Press.

Decoteau, C. L. (2013). The crisis of liberation: Masculinity, neo-liberalism, and HIV/AIDS in postapartheid South Africa. Men and Masculinities, 16(2), 139-159.

Disemelo, K. (2015). Black men as pink consumers? A critical reading of race, sexuality and the construction of the pink economy in South African queer consumer media. Unpublished $\mathrm{PhD}$ thesis. Johannesburg: University of the Witwatersrand.

du Pisani, K. (2001). Puritanism transfored: Afrikaner masculinities in the apartheid and postapartheid period. In R. Morrell (Ed.), Changing men in South Africa (pp. 157-175). Pietermaritzburg: University of Natal Press.

Gabrielatos, C., \& Marchi, A. (2012). Keyness: Appropriate metrics and practical issues. In Corpus-assisted Discourse Studies: More than the sum of Discourse Analysis and computing? Bologna: University of Bologna.

Hearn, J., \& Morrell, R. (2012). Reviewing hegemonic masculinities and men in Sweden and South Africa. Men and Masculinities, 15(1), 3-10.

Johnson, S. (1997). Theorizing language and masculinity. In S. Johnson \& U. H. Meinhof (Eds.), Language and masculinity (pp. 8-26). Oxford: Basil Blackwell.

Khounou, G. (2013). Men's health: An analysis of representations of men's health in the Sowetan newspaper. Communicatio, 39(2): 182-193.

Luyt, R. (2013). Constructing hegemonic masculinities in South Africa: The discourse and rhetoric of heteronormativity. Gender \& Language, 6(1), 47-77.

Mager, A. (2005). "One Beer, One Goal, One Nation, One Soul”: South African Breweries, Heritage, Masculinity and Nationalism 1960-1999. Past \& Present, 188(1), 163-194.

Mautner, G. (2009). Checks and balances: How corpus linguistics can contribute to CDA. In R. Wodak \& M. Meyer (Eds.), Methods of critical discourse analysis ( $2^{\text {nd }}$ edition) (pp. 122-143). Thousand Oaks: Sage.

McEnery, A., Tono, Y., \& Xiao, Z. (2006). Corpus-based language studies: An advanced resource book. London: Routledge.

Messerschmidt, J. W. (1993). Masculinities and crime critique and reconceptualization of theory. Boston: Rowman \& Littlefield.

Messner, M. (1992). Power at play: Sports and the problem of masculinity. Boston: Beacon.

Milani, T. M. (2013). Are "queers" really "queer"? Language, identity and same-sex desire in a South African online community. Discourse \& Society, 24(5), 615-633.

Milani, T. M. \& Shaikjee, M. (2013) A new South African man? Beer, masculinity and social change. In L. L. Atanga, S. E. Ellece, L. Litosseliti, \& J. Sunderland (Eds.), Gender and language in sub-Saharan Africa: Tradition, struggle, and change (pp. 131-148). Amsterdam: John Benjamins.

Morrell, R. (1998). Of boys and men: Masculinity and gender in South African studies. Journal of South African Studies, 24(4), 605-630.

Morrell, R., Jewkes, R., \& Lindegger, G. (2012). Hegemonic masculinity/masculinities in South Africa: Culture, power, and gender politics. Men and Masculinities, 15(1), 11-30.

Newburn, T., \& Stanko, E. A. (2013). Just Boys Doing Business? Men, Masculinities and 
Oostendorp, M. (2015). The multimodal construction of the identity of politicians: Constructing Jacob Zuma through prior texts, prior discourses and multiple modes. Critical Discourse Studies, 12(1), 39-56.

Pearce, M. (2008). Investigating the collocational behaviour of MAN and WOMAN in the BNC using Sketch Engine. Corpora, 3(1), 1-29.

Ratele, K. (2006). Ruling masculinity and sexuality. Feminist Africa, 6, 48-64.

Ratele, K. (2008). Ruling masculinities in post-apartheid South Africa. In A. Cornwall, S. Correa, \& S. Jolly (Eds.), Development with a body: Sexuality, human rights and development (pp. 121-135). London: Zed Books.

Ratele, K. (2014). Currents against gender transformation of South African men: Relocating marginality to the centre of research and theory of masculinities. NORMA: International Journal for Masculinity Studies, 9(1), 30-44.

Romaine, S. (2001). A corpus-based view of gender in British and American English. In M. Hellinger \& H. Bussman (Eds.), Gender across languages: The linguistic representation of women and men (Vol. 1, pp. 153-175). Amsterdam: John Benjamins.

Scott, M. (1999). WordSmith Tools help manual. Oxford: Mike Scott \& Oxford University Press.

Scott, M. (2012). WordSmith Tools version 6. Stroud: Lexical Analysis Software.

Sideris, T. (2005). "You have to change, and you don't know how!" Contesting what it means to be a man in a rural area of South Africa. In G. Reid \& L. Walker (Eds.), Men behaving differently: South African men since 1994 (pp. 111-138). Cape Town: Double Storey Books.

Sinclair, J. (1998). The lexical item. In E. Weigand (Ed.), Contrastive lexical semantics (pp. 1-24). Amsterdam: John Benjamins.

Stadler, J. (2008). Tsotis, coconuts, and wiggers: Black masculinity and contemporary South African media. In A. Hadland, E. Louw, S. Sesanti, \& H. Wasserman (Eds.), Power, politics and identity in South African media (pp. 343-363). Pretoria: HSRC Press.

Stewart, D. (2010). Semantic prosody: A critical evaluation. London: Routledge.

Stubbs, M. (2009). The search for units of meaning: Sinclair on empirical semantics. Applied Linguistics, 30(1), 115-137.

Unterhalter, E. (2000). The work of the nation: Heroic masculinity in South African autobiographical writing of the anti-apartheid struggle. The European Journal of Development Research, 12(2), 157-178.

van Leeuwen, T. (1996). The representation of social actors. In C. Caldas-Coulthard \& M. Coulthard (Eds.), Texts and practices: Readings in Critical Discourse Analysis (pp. 3270). London: Routledge.

Viljoen, S. (2008). Masculine ideals in post-apartheid South Africa: The rise of men's glossies. In A. Hadland, E. Louw, S. Sesanti, \& H. Wasserman (Eds.), Power, politics and identity in South African media (pp. 312-342). Pretoria: HSRC Press.

Walker, L. (2005). Negotiating the boundaries of masculinity in post-apartheid South Africa. In G. Reid \& L. Walker (Eds.), Men behaving differently: South African men since 1994 (pp. 161-182). Cape Town: Double Storey Books.

Xiao, Z., \& McEnery, A. (2005). Two approaches to genre analysis: Three genres in Modern American English. Journal of English Linguistics, 33(1), 62-82.

Xiao, Z., \& McEnery, T. (2006). Collocation, semantic prosody, and near synonymy: A cross-linguistic perspective. Applied Linguistics, 27(1), 103-129. 
Table 1. Query terms for building masculinity sub-corpus

\begin{tabular}{cccc}
\hline \hline masculinity & manhood & man/men & bloke \\
boet/boetie & boy & bra(h) & bro \\
brother & bru & chief & dude \\
guy & hunk & lad & mate \\
oke & ou & stallion & stud \\
\hline \hline
\end{tabular}

Table 2. Top 75 Keywords in Masculinity Sub-Corpus

Sport

AUS, FRA, SUNDOWNS, VILLIERS, CHAMPIONSHIP, OVERS, GER, WICKETS, STORMERS, BOWLING, RUS, FINALS, INNINGS, CHAMPION, SPRINGBOK, ZEALAND, RACING, GOALS, USA, LEG, CELTIC, CHEETAHS, SINGLES, RUGBY, COACH, PIRATES, ROUND, AUSTRALIA, CRICKET, SQUAD, CAPTAIN, CHAMPIONS, PLAYER, PLAYERS, WIN, PLAYING, GAME, SIDE, SPORT, PLAY, ENG, RSA

Violence/Crime RAPE, MAGISTRATE'S, ROBBERY, SUSPECT, SHOOTING, GANG, ARMED, SHOT, KILLED, DEAD

Kinship

GIRLS, GIRL, WOMEN'S, SISTER, MALE, FATHER, SON, FAMILY

Ambiguous

INJURED, SCORED, INJURY, FAVOURITE, RAN, FALL, BEAT

Misc.

COLLEGE, LOOKED, ARTICLE, MISSING, OLD, PISTORIUS, TOUGH

Table 3. Top Collocates of General Masculinity Terms in Sub-Corpus (DICE coefficient)

\begin{tabular}{lcl}
\hline \hline Search Term & Frequency & Collocates \\
\hline masculinity & 702 & $\begin{array}{l}\text { men (71), notions (31), South African (33), identity (26), crisis } \\
(26), \text { violence (35), Africa (19), issues (21), women (23), white } \\
\end{array}$ \\
& $\begin{array}{l}\text { (17), culture/al (31), associated (17), boys (15), gender (26), } \\
\text { constructions (17), black (15), femininity (15), positive (13), } \\
\text { social (19), racial (21) }\end{array}$ \\
& $\begin{array}{l}\text { passage (66), rite(s) (32), boyhood (21), ritual(s) (25), initiation } \\
\text { (26), proving (15), circumcision (20), teachings (10), define (9), } \\
\text { transition (10), boy (7), definition (8), Xhosa (12), myth (8), } \\
\text { people (6), journey (17), redefin(ing) (12), childhood (10), } \\
\text { navigate (6), symbols (6) }\end{array}$ \\
&
\end{tabular}


Table 4. Top Collocates of Most Frequent Male Types in Sub-Corpus (DICE coefficient)

\begin{tabular}{|c|c|c|}
\hline Search Term & Frequency & Collocates \\
\hline $\operatorname{man}$ & 43,722 & $\begin{array}{l}\text { woman (1476), old (1765), young (1463), match (303), squad } \\
\text { (275), black (622), white ( } 577) \text {, South African ( } 834) \text {, African } \\
\text { (492), group (410), family (284), killed (365), named (172), } \\
\text { boys (278), made ( } 277) \text {, allegedly (872), arrested (2025), good } \\
(245) \text {, shot (674), life ( } 217)\end{array}$ \\
\hline guy & 4,493 & 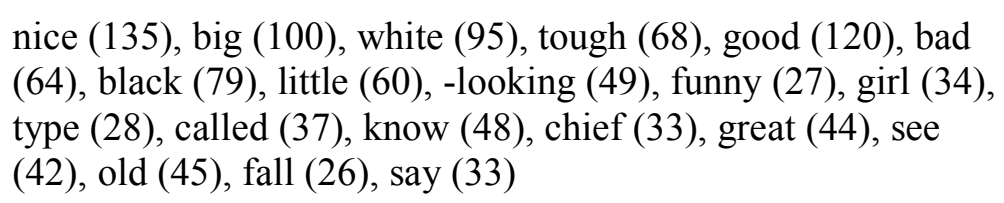 \\
\hline bloke & 576 & $\begin{array}{l}\text { crikey (8), deaf (11), nice (32), yelled (7), uncomplicated (6), } \\
\text { ordinary (13), thoroughly (7), people (5), suit (11), remark (6), } \\
\text { old-fashioned (6), distinguished (6), Aussie (6), easygoing (4), } \\
\text { salt-of-the-earth (6), appoint (5), unassuming (4), fearsome (4), } \\
\text { demonstrate (4), intact (4) }\end{array}$ \\
\hline
\end{tabular}

Table 5. Top Keywords of Address Terms in the Sub-Corpus

\begin{tabular}{lcl}
\hline \hline Term & Frequency & Top Keywords \\
\hline bot & HOWZIT, BOWLS, RUGBY, LADY, MARKER, \\
& STADIUMS, HANDICAP, CANDID, WHITES, TRIPS, \\
& WINE, MORNINGSIDE, AFRIKAANS, RACISM, \\
& SRPINGBOKS, COMPETITION, BRAAI, FARM, \\
& WEEKEND, CAMPAIGN, MUNICIPAL, FLASH \\
bru & COFFEE, LEKKER, OOSTERBROEK, BEANS, HEY, \\
& HOWZIT, WINE, THEATRE, SURFING, SHOW, BEER, \\
& VUVUZELA, PHOTOGRAPHER, CALL, FESTIVAL, \\
& BEACH, MUSICIANS, MUSIC, WILDLIFE, FACEBOOK, \\
& BRIGHT, SEA, PERFORMERS, DOCUMENTARY, JAZZ \\
bro & MBEKI, GROWTH, ECONOMY, SECTOR, ELECTRICITY, \\
& PRICES, FINANCE, TRADE, POLICY, INCREASE, \\
& INVESTMENT, DISPATCH, LEADERSHIP, ESKOM, \\
& BILLION, CRISIS, INFRASTRUCTURE, COMPANIES, \\
& COSATU, DEMAND, GLOBAL, BUDGET, LABOUR, \\
& ELECTION, DELIVERY, BUSINESSES, ENERGY, \\
& INCREASED, SUPPLY, COMMISSION \\
\hline
\end{tabular}

